\title{
Fabrication of a Needle Microsensor and Its Applications in the Detection of Dissolved Oxygen
}

\author{
Yuxin Fang, ${ }^{1}$ Di Zhang, ${ }^{2}$ Qing Xia, ${ }^{1}$ Shouhai Hong, ${ }^{1}$ Yuan Xu, ${ }^{1}$ and Yi Guo ${ }^{1}$ \\ ${ }^{1}$ Research Center of Experimental Acupuncture Science, College of Acumox and Tuina, \\ Tianjin University of Traditional Chinese Medicine, Tianjin 300193, China \\ ${ }^{2}$ The Key Laboratory of Bioactive Materials, College of Life Science, Nankai University, No. 94 Weijin Road, Tianjin 300071, China
}

Correspondence should be addressed to Yi Guo; guoyi_168@163.com

Received 13 January 2015; Revised 24 March 2015; Accepted 27 March 2015

Academic Editor: Yanxia Hou

Copyright (C) 2015 Yuxin Fang et al. This is an open access article distributed under the Creative Commons Attribution License, which permits unrestricted use, distribution, and reproduction in any medium, provided the original work is properly cited.

\begin{abstract}
A novel needle microsensor measurement system was fabricated and applied to determine the concentration of dissolved oxygen. Platinum nanoparticles were employed to modify the surface of copper-core electrode in order to improve electrochemical response signal. The homemade electrode displayed efficient electrocatalytic reduction activity towards dissolved oxygen. The sensor responded linearly to dissolved oxygen in the range of $10 \mu \mathrm{M}$ to $0.195 \mathrm{mM}$ and had a remarkable sensitivity of $9.02 \mu \mathrm{A} / \mathrm{mM}$. In addition, it showed an excellent reproducibility, stability, and selectivity. These results indicated that the needle microsensor when used, could yield good performance. Moreover, it is believed to be a potential tool for studying specific substances at a cellular level or in vivo in future.
\end{abstract}

\section{Introduction}

The reliable determination of dissolved oxygen in aqueous solution is of great importance in various applications such as environmental and industrial analysis [1]. Moreover, biochemical pathways in living cells involve the consumption of dissolved oxygen from the environment. Hence, the dynamic monitoring of dissolved oxygen for in vitro cell assays and in vivo tests is also an important task on cellular signaling [2]. Different detection techniques including fluorescence $[3,4]$, nuclear magnetic resonance (NMR) [5], electrochemiluminescence $[6,7]$, and electrochemistry $[8,9]$ have been reported in literature for this purpose. Among these, the electrochemical method has played a significant role in the expanding field of detection research because of its high selectivity, quick response, and good reproducibility. Tsai et al. reported dissolved oxygen electrochemical sensors based on glassy carbon electrode (GCE) and indium tin oxide electrode (ITO) modifying silver nanoparticles [8]. Chou et al. proposed a new gold-solid polymer electrolyte sensor for detecting dissolved oxygen in water [10]. Also, a novel dissolved oxygen electrochemical sensor based on metal insulator semiconductor field effect transistor (MISFET) structure with Pt-LaF 3 mixture film had been developed by $\mathrm{Na}$ et al. [11].

With advances in electroanalytical chemistry and microelectronics technology, using microelectrodes as indispensable tools for evaluating chemistries has attracted particular attention in the past few years. In comparison with the conventional macroscale electrodes, microelectrodes have several advantageous characteristics such as rapid response, increased signal-to-noise ratio, low ohmic $(i-R)$ drop, small capacitive-charging currents, and enhanced rates of masstransport [12-14]. However, microelectrodes usually generate low currents, which may constitute a major problem to the signal detection. One main solution to overcome this problem is to modify microelectrodes with metal nanoparticles in order to artificially increase the active surface area of such electrodes. To date, microelectrodes have been successfully used to measure numerous chemical species and parameters in microenvironment including $\mathrm{pH}$, ammonia, $\mathrm{Mn}^{2+}$, hydrogen peroxide, $\mathrm{HS}^{-}$, and other dissolved gases and ions [1518]. To our knowledge, there are only a few papers that have reported the usage of microelectrodes for dissolved oxygen sensing. 


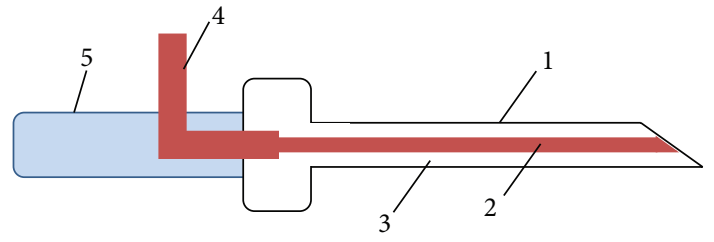

(a)

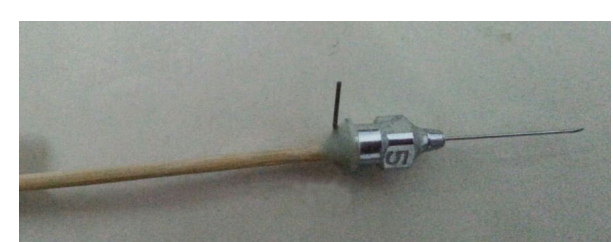

(b)

FIGURE 1: The fabrication of needle-tip microelectrode. (a) The structure diagram of microelectrode: 1: stainless steel syringe needle; 2 : coppercore electrode (copper enamelled wire, $\varphi=0.16 \mathrm{~mm}$ ); 3: epoxy resin glue; 4: working electrode lead wire (copper enamelled wire, $\varphi=$ $0.71 \mathrm{~mm}$ ); 5: fixed link. (b) The picture of microelectrode.

In this work, a needle microsensor was prepared and applied to detection of dissolved oxygen. Platinum nanoparticle (PtNP) which is one of the most researched noble metals was used to modify the surface of copper-core electrode in order to enhance electrochemically catalytic activity of the electrode. The tip of the electrode was characterized by stereomicroscope and scanning electron microscope (SEM), and the electrochemical performance of electrode was studied. The results showed that the homemade electrode with good electroreduction activity towards dissolved oxygen was successfully prepared. Furthermore, it can be used as a powerful tool for certain material testing at the level of cells or in vivo.

\section{Experimental}

2.1. Reagents and Materials. Potassium hexachloroplatinate $\left(\mathrm{K}_{2} \mathrm{PtCl}_{6}\right)$ was purchased from Sigma-Aldrich (USA). Copper enamelled wire $(\varphi=0.16 \mathrm{~mm}, 0.71 \mathrm{~mm})$, rubber tube $(\varphi=3 \mathrm{~mm}), 5$-gauge stainless steel syringe needle, sand paper (1200 mesh), bamboo sticks $(\varphi=2 \mathrm{~mm})$, phosphate buffer solution (PBS, $\mathrm{pH}$ 7.2-7.6), and aluminium oxide polishing powder $(\varphi=0.05 \mu \mathrm{m})$ were all obtained from Tianjin HuaShengYuan Technology Co., LTD. (China). Nitrogen gas holder and oxygen tank were provided by Tianjin Six-Party Industrial Gases Co., LTD. (China). All agents used in this study were of analytical grade, and doubly distilled water was used throughout. The $\mathrm{O}_{2}$-saturated standard solution was produced by bubbling PBS with pure $\mathrm{O}_{2}$ at room temperature for $30 \mathrm{~min}$, in which the dissolved oxygen content was $2.6 \times$ $10^{-4} \mathrm{M}$ calculated from its saturated solubility [19].

2.2. Apparatus. The electrochemical measurements were carried out using a LK3200 electrochemical workstation (Tianjin Lanlike Chemical High Electronic Technology Co., LTD., China). A conventional three-electrode system, containing the PtNPs film modified self-made copper-core microelectrode $(0.5 \mathrm{~mm}$ diameter) as a working electrode, a platinum wire ( $1 \mathrm{~mm}$ diameter) as a counter electrode, and an $\mathrm{Ag} / \mathrm{AgCl}$ electrode (saturated with $\mathrm{KCl}$ ) as a reference electrode, was employed for all electrochemical experiments.

Stereomicroscope images were obtained by using Olympus SZ61 instrument (Japan). Scanning electron microscope (SEM) images were gained by using Nova NanoSEM 430 instrument (Netherlands).

2.3. The Fabrication of Needle Copper-Core Microelectrode. The fabrication of needle copper-core microelectrode (as

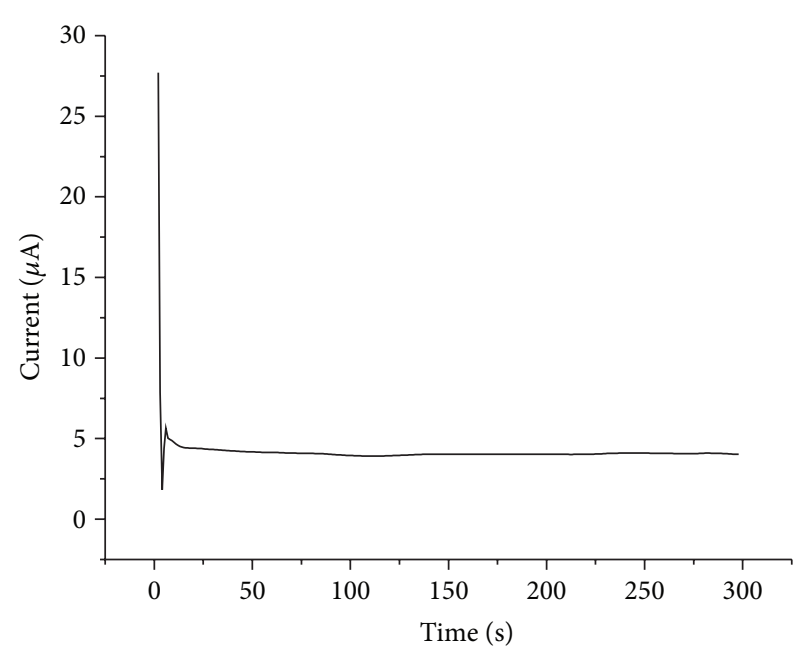

Figure 2: Current versus time curve of electrodeposition process. Potential: $-0.2 \mathrm{~V}$ versus $\mathrm{Ag} / \mathrm{AgCl}$.

shown in Figure 1) was divided into four steps. At first, copper enamelled wire $(\varphi=0.16 \mathrm{~mm})$ was threaded into the syringe needle. Secondly, one end of the copper enamelled wire was immobilized with the tip of syringe needle using epoxy resin glue. Thirdly, the other end of the copper enamelled wire which was located in the tail of syringe needle was crosslinked with another fraction of copper enamelled wire $(\varphi=$ $0.71 \mathrm{~mm}$ ), which led to the working electrode wire. Lastly, the tip of the syringe needle was burnished on sand paper and $0.05 \mu \mathrm{m}$ aluminum oxide polishing powder to obtain a flat and smooth surface.

2.4. Electrode Surface Modification. Before modification, the self-made copper-core microelectrode was ultrasonically cleaned with ethanol and double distilled water for $5 \mathrm{~min}$ to remove the contaminants. To enhance the catalytic activity of electrode, PtNPs were employed in this work. The microelectrode was immersed in $40 \mathrm{~mL}$ deposition solution (0.1 M PBS containing $10 \mathrm{mM} \mathrm{K}_{2} \mathrm{PtCl}_{6}$ ) and a constant potential at $-0.2 \mathrm{~V}$ for $300 \mathrm{~s}$ was applied to obtain the PtNPs modified coppercore microelectrode.

\section{Results and Discussion}

3.1. Electrodeposition of Platinum Nanoparticles. Figure 2 showed the typical electrochemical deposition process of 


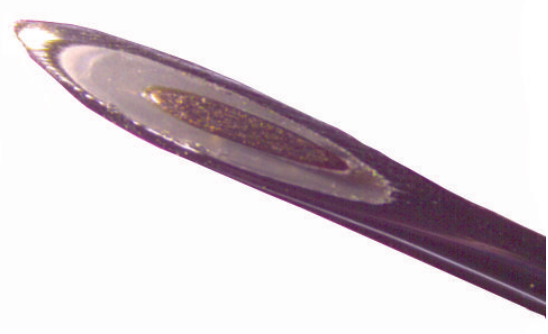

(a)

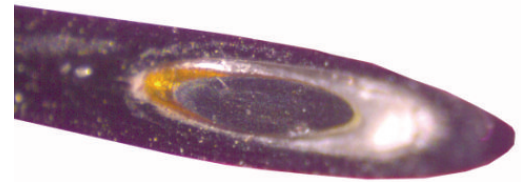

(b)

FIGURE 3: Stereomicroscope images of the tip of copper-core syringe needle. (a) Bare copper electrode section, (b) copper electrode section with PtNPs modification.

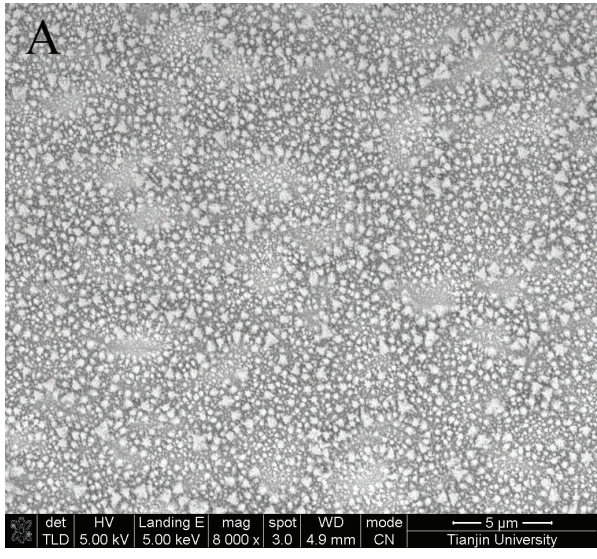

(a)

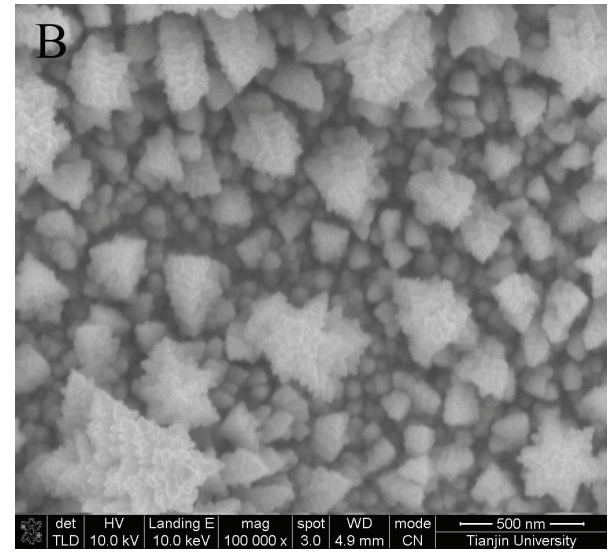

(b)

FIgURE 4: SEM images of PtNPs modified on the surface of microelectrode under different magnification.

nanoplatinum particles. As we all know, the platinum ions were reduced to platinum atoms by applying a constant negative voltage, and platinum atoms will accumulate on the electrode surface as time proceeds. As shown in Figure 2, the curve of electrodeposition is smooth, indicating that the tip of self-made copper-core microelectrode was cured and polished well. Therefore, a compact platinum nanofilm can be obtained by this method.

3.2. Morphology of the Tip of Self-Made Copper-Core Microelectrode. Figure 3 demonstrates stereomicroscope images under fifty times amplification of the tip of the self-made microelectrode. From Figure 3(a), the surface of the electrode is very smooth, which is the precondition of electrochemical detection. When the surface of electrode was modified with the PtNPs (Figure 3(b)), a bright and uniform film was formed. This provided evidence to support the stability of the curve of electrodeposition. Figures 4(a) and 4(b) reveal the SEM images of PtNPs modified on the surface of microelectrode under different magnification. As can be seen, PtNPs were successfully distributed on the microelectrode surface by electrodeposition. And the higher magnification of SEM image (b) clearly shows that some PtNPs have been associated to form laminated structure, which could amplify specific surface area of microelectrode and enhance the current response of the sensor. In conclusion, the results show that the homemade PtNPs modified copper-core microelectrode could ensure the smooth conduct of following electrochemical experiments.

\subsection{Electrochemical Behavior of Homemade Microelectrode} towards the Dissolved Oxygen. As shown in Figure 5, the electrochemical response of PtNPs modified copper-core microelectrode towards dissolved oxygen was investigated. Figure 5(a) demonstrates cyclic voltammograms of PtNPs modified copper-core microelectrode in $\mathrm{pH} 7.0 \mathrm{O}_{2}$-saturated PBS (A) and $\mathrm{N}_{2}$-saturated PBS (B). It was clear that there was not any redox reaction when the self-made electrode was immersed in $\mathrm{N}_{2}$-saturated PBS (curve B). In contrast, a remarkable reduction peak at $-0.5 \mathrm{~V}$ was observed in $\mathrm{O}_{2}$ saturated PBS (curve A). This showed that the self-made copper-core electrode can carry on catalytic activity towards dissolved oxygen. It has been reported that there is an efficient four-electron reduction reaction of dissolved oxygen on 


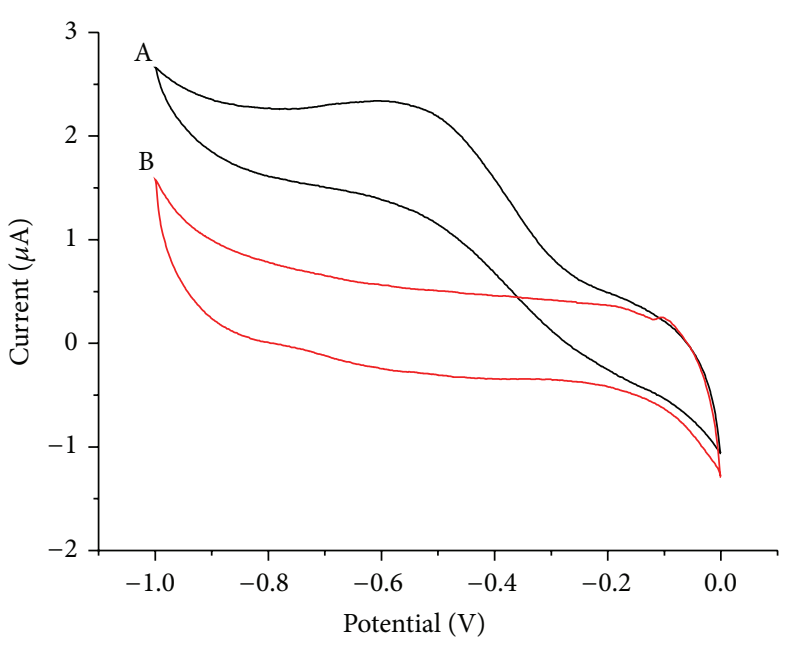

A: $\mathrm{Cu}$-PtNPs $\left(\mathrm{O}_{2}\right.$-saturated PBS)

B: Cu-PtNPs $\left(\mathrm{N}_{2}\right.$-saturated PBS)

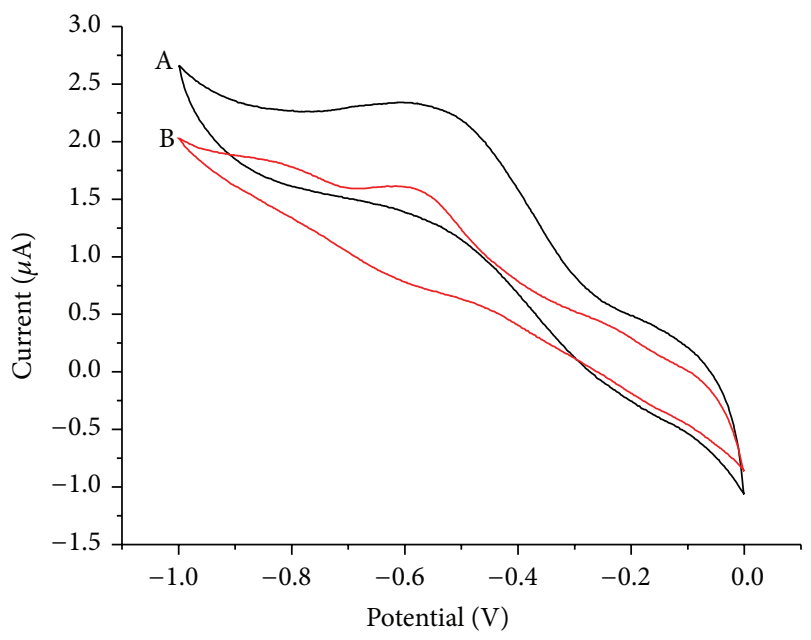

A: $\mathrm{Cu}$-PtNPs $\left(\mathrm{O}_{2}\right.$-saturated PBS) B: $\mathrm{Cu}\left(\mathrm{O}_{2}\right.$-saturated $\left.\mathrm{PBS}\right)$

(a)

(b)

Figure 5: (a) Cyclic voltammograms of PtNPs modified copper-core microelectrode in pH $7.0 \mathrm{O}_{2}$-saturated PBS (A) and $\mathrm{N}_{2}$-saturated PBS (B). (b) Cyclic voltammograms of PtNPs modified copper-core microelectrode (A) and bare copper-core microelectrode (B) in $\mathrm{pH} 7.0 \mathrm{O}_{2}{ }^{-}$ saturated PBS.

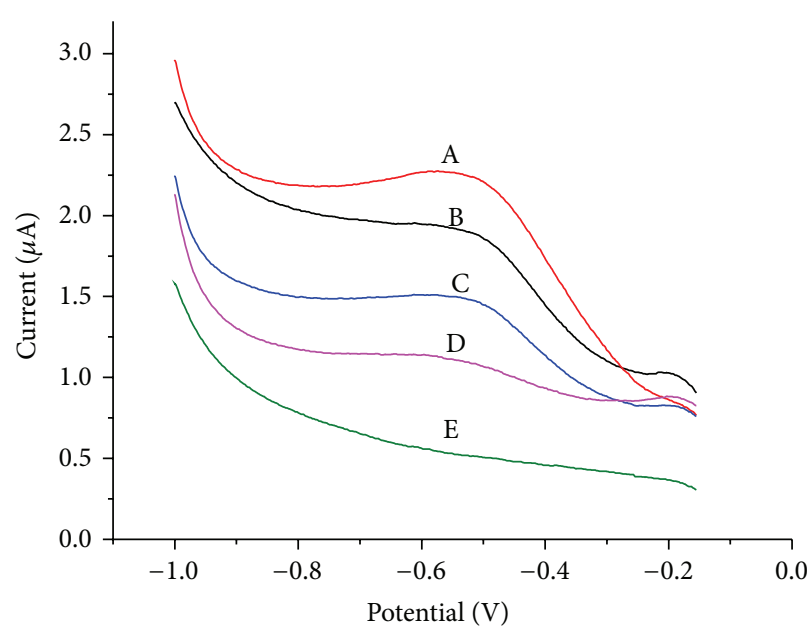

(a)

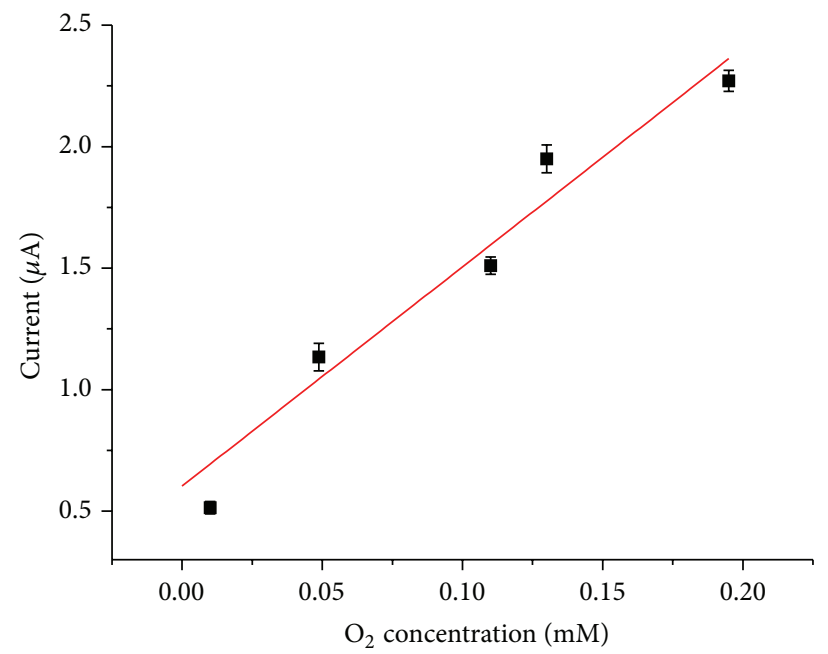

(b)

FIGURE 6: Simultaneous determination of dissolved oxygen at PtNPs modified copper-core microelectrode by cyclic voltammetry in $0.1 \mathrm{M}$ PBS ( $\mathrm{pH}$ 7.0); (a) reduction waves of the cyclic voltammograms and (b) calibration curve for dissolved oxygen.

the surface of electrode [20]. The reaction equation is described as follows:

$$
\mathrm{O}_{2}+2 \mathrm{H}_{2} \mathrm{O}+4 \mathrm{e}^{-} \longrightarrow 4 \mathrm{OH}^{-}
$$

Besides, virtually no current in the anodic sweep was obtained from curve A, indicating a totally irreversible process of dissolved oxygen reduction process. These results were in accordance with other reported electrochemical dissolved oxygen sensors [21-24].

Figure 5(b) shows cyclic voltammograms of PtNPs modified copper-core microelectrode (A) and bare copper-core microelectrode (B) in $\mathrm{O}_{2}$-saturated PBS. The dissolved oxygen was reduced to a variable extent on these two electrodes. For the PtNPs modified copper-core microelectrode (curve A), the increase of the peak current and the positive shift of the potential indicated that the PtNPs modified microelectrode has a larger active surface area and better electrocatalytic activity towards dissolved oxygen than bare coppercore microelectrode.

Figure 6 displays the simultaneous determination of dissolved oxygen at PtNPs modified copper-core microelectrode by cyclic voltammetry in $0.1 \mathrm{M}$ PBS (pH 7.0). Different volumes of $\mathrm{O}_{2}$-saturated solution were spiked into $\mathrm{N}_{2}$-saturated 
TABLE 1: Comparison of performance of various dissolved oxygen sensors.

\begin{tabular}{|c|c|c|c|}
\hline Electrode & Detection limit $(\mu \mathrm{M})$ & Linear range & Reference \\
\hline Nickel-salen/Pt & 22.2 & $0.12 \mathrm{mM}-0.29 \mathrm{mM}$ & {$[25]$} \\
\hline CNF/GCE & 0.07 & $0.1 \mu \mathrm{M}-78 \mu \mathrm{M}$ & {$[26]$} \\
\hline Vitamin $\mathrm{B}_{12} / \mathrm{RDE}$ & 9.2 & $15 \mu \mathrm{M}-45 \mu \mathrm{M}$ & {$[27]$} \\
\hline$\beta \mathrm{CDSH} / \mathrm{FeTMPyP} / \beta \mathrm{CDSHAuNP} / \mathrm{Au}$ & 0.6 & $6.3 \mu \mathrm{M}-0.2 \mathrm{mM}$ & {$[28]$} \\
\hline GNP/MWNTs-FeTMAPP/Au & 0.38 & $0.52 \mu \mathrm{M}-0.18 \mathrm{mM}$ & {$[29]$} \\
\hline PtNPs/Cu-core microelectrode & 3.33 & $10 \mu \mathrm{M}-0.195 \mathrm{mM}$ & This work \\
\hline
\end{tabular}

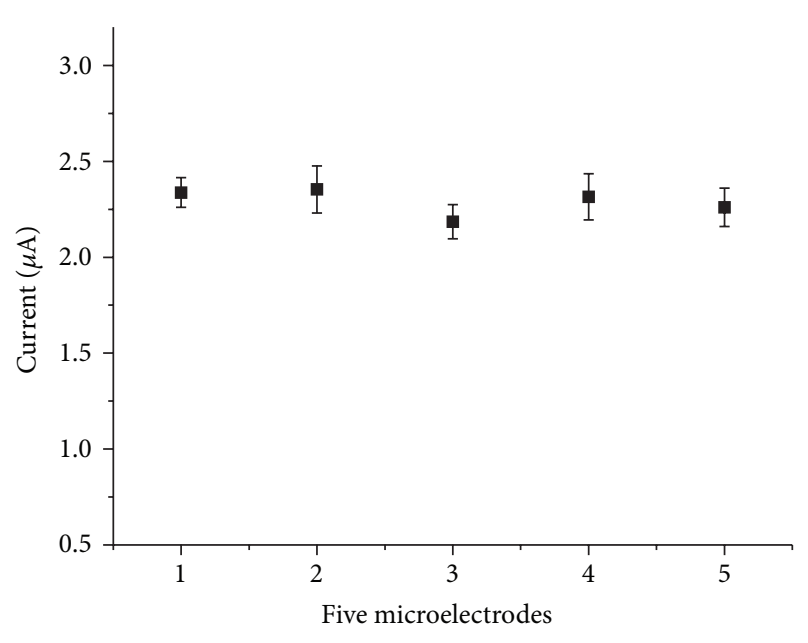

(a)

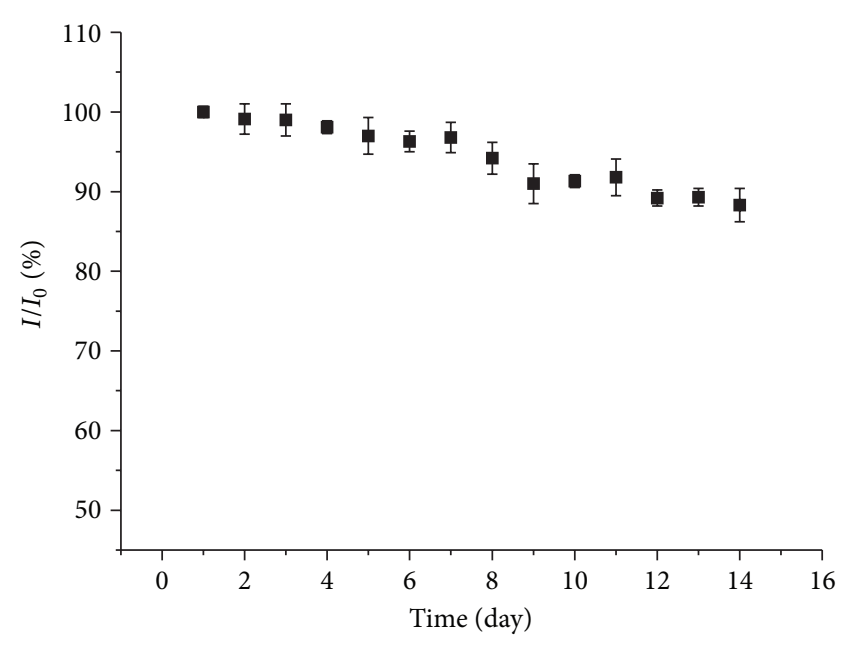

(b)

FIGURE 7: (a) The reproducibility research of self-made microelectrode; (b) the stability of microelectrode stored at refrigerator temperature for two weeks in PBS (pH 7.0) with dropwise addition of $0.1 \mathrm{mM}$ dissolved oxygen.

PBS in order to control the concentration of dissolved oxygen. From Figure 6(a), the reductive peak current increased with increasing of the concentrations of dissolved oxygen. The calibration curve obtained with the reduction peak currents was shown in Figure 6(b). The slope (sensitivity) of the plot was $9.02 \mu \mathrm{A} / \mathrm{mM}$ (correlation coefficient =0.96). In the range of $10 \mu \mathrm{M}$ to $0.195 \mathrm{mM}$, the current responses were proportional to the dissolved oxygen concentrations. The detection limit $(S / N=3)$ was $3.33 \mu \mathrm{M}$. Various dissolved oxygen sensors have been summarized in Table 1 with respect to the detection limit and the linear range. It reveals that the proposed microelectrode is potentially useful for determination of dissolved oxygen.

For the purpose of the biological applications, the responses of common interferences on the proposed sensor were investigated and the results were summarized in Table 2. The sensor response was evaluated in presence of $0.1 \mathrm{mM}$ ascorbic acid, uric acid, 4-aminophenol, $\mathrm{Ca}^{2+}, \mathrm{Na}^{+}, \mathrm{NO}_{3}{ }^{-}$, $\mathrm{SO}_{4}{ }^{2-}$, and hydroquinone at $0.1 \mathrm{mM}$ dissolved oxygen. As expected, the observed influences are all less than $5 \%$ on the dissolved oxygen response.

As we all know, the reproducibility and stability of electrode are also important parameters for evaluating the performance of a sensor. The device-to-device reproducibility was investigated from its response to dissolved oxygen saturated solution at five microelectrodes independently (Figure 7(a)),
TABLE 2: Interference effect on the detection of dissolved oxygen with the proposed sensor in PBS at $\mathrm{pH} 7.0$ (applied potential: $-0.3 \mathrm{~V})$.

\begin{tabular}{lc}
\hline Species added & Response ratio (\%) \\
\hline Ascorbic acid & 4.8 \\
Uric acid & 3.9 \\
4 -Aminophenol & 4.2 \\
$\mathrm{Ca}^{2+}$ & 2.1 \\
$\mathrm{Na}^{+}$ & 1.2 \\
$\mathrm{NO}_{3}{ }^{-}$ & 1.5 \\
$\mathrm{SO}_{4}{ }^{2-}$ & 2.6 \\
$\mathrm{Hydroquinone}^{-}$ & 4.9 \\
Dissolved oxygen & 100 \\
\hline
\end{tabular}

and the relative standard deviation (RSD) was calculated to be $3.0 \%$. Besides, the microelectrode was stored at refrigerator temperature and measured every day; it retained about $88.3 \%$ of its original sensitivity after 2 weeks (Figure $7(\mathrm{~b})$ ). Therefore, the self-made PtNPs modified copper-core microelectrode exhibited an acceptable reproducibility and longterm stability. The above results fully indicated that the electrochemical performance of self-made microelectrode towards dissolved oxygen is good, and it can be used as 
a candidate to detect specific substance at a cellular level or in vivo studies in future.

\section{Conclusions}

In the present work, a novel needle microsensor was prepared and can be applied to determine the concentration of dissolved oxygen. The tip of the microelectrode was polished on sand paper and polishing cloth, obtaining a smooth and flat surface. PtNPs were successfully electrodeposited on the surface of the self-control microelectrode. The resulting microsensor showed an excellent electrochemical property towards dissolved oxygen. Additionally, the current work exhibited a good potential for substances determination in vivo.

\section{Conflict of Interests}

The authors declare that there is no conflict of interests regarding the publication of this paper.

\section{Acknowledgments}

The financial supports from National Natural Science Foundation of China (Grant no. 81173204) and Application Basis and Advanced Technology Research Project of Tianjin (Grant no. 15JCQNJC10800) are acknowledged.

\section{References}

[1] P. Sahoo, R. Ananthanarayanan, N. Malathi, M. P. Rajiniganth, N. Murali, and P. Swaminathan, "Pulsating potentiometric titration technique for assay of dissolved oxygen in water at trace level," Analytica Chimica Acta, vol. 669, no. 1-2, pp. 17-24, 2010.

[2] Y. Eminaga, M. Brischwein, J. Wiest, J. Clauss, S. Becker, and B. Wolf, "Self calibration of a planar dissolved oxygen sensor," Sensors and Actuators B: Chemical, vol. 177, pp. 785-791, 2013.

[3] C. S. Chu and Y. L. Lo, "Optical fiber dissolved oxygen sensor based on Pt(II) complex and core-shell silica nanoparticles incorporated with sol-gel matrix," Sensors and Actuators B: Chemical, vol. 151, no. 1, pp. 83-89, 2010.

[4] T. Sakai, H. Takio, N. Teshima, and H. Nishikawa, "Extractionflow injection spectrofluorimetric measurement of dissolved oxygen in environmental waters using 2-thionaphthol," Analytica Chimica Acta, vol. 438, no. 1-2, pp. 117-121, 2001.

[5] N. Nestle, T. Baumann, and R. Niessner, "Oxygen determination in oxygen-supersaturated drinking waters by NMR relaxometry," Water Research, vol. 37, no. 14, pp. 3361-3366, 2003.

[6] Z. Lin, Y. Liu, and G. Chen, " $\mathrm{TiO}_{2} / \mathrm{Nafion}$ film based electrochemiluminescence for detection of dissolved oxygen," Electrochemistry Communications, vol. 10, no. 10, pp. 1629-1632, 2008.

[7] J. Rong, Y. Chi, Y. Zhang, L. Chen, and G. Chen, "Enhanced electrochemiluminescence of luminol- $\mathrm{O}_{2}$ system at goldhydrophobic ionic liquid-water interface," Electrochemistry Communications, vol. 12, no. 2, pp. 270-273, 2010.

[8] T.-H. Tsai, S. Thiagarajan, and S.-M. Chen, "Green synthesis of silver nanoparticles using ionic liquid and application for the detection of dissolved oxygen," Electroanalysis, vol. 22, no. 6, pp. 680-687, 2010.
[9] C.-C. Yang, A. S. Kumar, and J.-M. Zen, "Electrocatalytic reduction and determination of dissolved oxygen at a preanodized screen-printed carbon electrode modified with palladium nanoparticles," Electroanalysis, vol. 18, no. 1, pp. 64-69, 2006.

[10] T. C. Chou, K. M. Ng, and S. H. Wang, "Gold-solid polymer electrolyte sensor for detecting dissolved oxygen in water," Sensors and Actuators, B: Chemical, vol. 66, no. 1, pp. 184-186, 2000.

[11] X. Na, W. Niu, H. Li, and J. Xie, "A novel dissolved oxygen sensor based on MISFET structure with Pt-LaF ${ }_{3}$ mixture film," Sensors and Actuators, B: Chemical, vol. 87, no. 2, pp. 222-225, 2002.

[12] S. G. Weber, "Signal-to-noise ratio in microelectrode-arraybased electrochemical detectors," Analytical Chemistry, vol. 61, no. 4, pp. 295-302, 1989.

[13] A. Gholizadeh, S. Shahrokhian, A. Iraji Zad et al., "Fabrication of sensitive glutamate biosensor based on vertically aligned CNT nanoelectrode array and investigating the effect of CNTs density on the electrode performance," Analytical Chemistry, vol. 84, no. 14, pp. 5932-5938, 2012.

[14] Y.-P. Chen, Y. Zhao, J. Chu et al., "Fabrication and characterization of an innovative integrated solid-state microelectrode," Electrochimica Acta, vol. 55, no. 20, pp. 5984-5989, 2010.

[15] A. V. Mokrushina, M. Heim, E. E. Karyakina, A. Kuhn, and A. A. Karyakin, "Enhanced hydrogen peroxide sensing based on Prussian Blue modified macroporous microelectrodes," Electrochemistry Communications, vol. 29, pp. 78-80, 2013.

[16] P. J. Brendel and G. W. Luther III, "Development of a gold amalgam voltammetric microelectrode for the determination of dissolved $\mathrm{Fe}, \mathrm{Mn}, \mathrm{O}_{2}$, and $\mathrm{S}(-\mathrm{II})$ in porewaters of marine and freshwater sediments," Environmental Science \& Technology, vol. 29, no. 3, pp. 751-761, 1995.

[17] P. Jeroschewski, C. Steuckart, and M. Kuhl, "An amperometric microsensor for the determination off $\mathrm{H}_{2} \mathrm{~S}$ in aquatic environments," Analytical Chemistry, vol. 68, no. 24, pp. 4351-4357, 1996.

[18] C. E. Reimers, "Applications of microelectrodes to problems in chemical oceanography," Chemical Reviews, vol. 107, no. 2, pp. 590-600, 2007.

[19] H. X. Ju and C. Z. Shen, "Electrocatalytic reduction and determination of dissolved oxygen at a poly(nile blue) modified electrode," Electroanalysis, vol. 13, no. 8-9, pp. 789-793, 2001.

[20] A. Kongkanand and S. Kuwabata, "Oxygen reduction at silver monolayer islands deposited on gold substrate," Electrochemistry Communications, vol. 5, no. 2, pp. 133-137, 2003.

[21] D. Zhang, Y. Fang, Z. Miao, M. Ma, and Q. Chen, "Electrochemical determination of dissolved oxygen based on three dimensional electrosynthesis of silver nanodendrites electrode," Journal of Applied Electrochemistry, vol. 44, no. 3, pp. 419-425, 2014.

[22] F. S. Damos, R. C. S. Luz, A. A. Tanaka, and L. T. Kubota, "Dissolved oxygen amperometric sensor based on layer-bylayer assembly using host-guest supramolecular interactions," Analytica Chimica Acta, vol. 664, no. 2, pp. 144-150, 2010.

[23] H.-F. Cui, J.-S. Ye, W.-D. Zhang, J. Wang, and F.-S. Sheu, "Electrocatalytic reduction of oxygen by a platinum nanoparticle/ carbon nanotube composite electrode," Journal of Electroanalytical Chemistry, vol. 577, no. 2, pp. 295-302, 2005.

[24] P. G. Osborne, X. Li, Y. Li, and H. Han, "Oxygen-sensing microdialysis probe for in vivo use," Journal of Neuroscience Research, vol. 63, no. 2, pp. 224-232, 2001. 
[25] C. S. Martin, T. R. L. Dadamos, and M. F. S. Teixeira, "Development of an electrochemical sensor for determination of dissolved oxygen by nickel-salen polymeric film modified electrode," Sensors and Actuators B: Chemical, vol. 175, pp. 111117, 2012.

[26] L. N. Wu, X. J. Zhang, and H. X. Ju, "Amperometric glucose sensor based on catalytic reduction of dissolved oxygen at soluble carbon nanofiber," Biosensors and Bioelectronics, vol. 23, no. 4, pp. 479-484, 2007.

[27] M. S. Lin, H. J. Leu, and C. H. Lai, "Development of Vitamin $\mathrm{B}_{12}$ based disposable sensor for dissolved oxygen," Analytica Chimica Acta, vol. 561, no. 1-2, pp. 164-170, 2006.

[28] F. S. Damos, R. C. S. Luz, A. A. Tanaka, and L. T. Kubota, "Dissolved oxygen amperometric sensor based on layer-bylayer assembly using host-guest supramolecular interactions," Analytica Chimica Acta, vol. 664, no. 2, pp. 144-150, 2010.

[29] Y. Liu, Y. L. Yan, J. Lei, F. Wu, and H. Ju, "Functional multiwalled carbon nanotube nanocomposite with iron picket-fence porphyrin and its electrocatalytic behavior," Electrochemistry Communications, vol. 9, no. 10, pp. 2564-2570, 2007. 

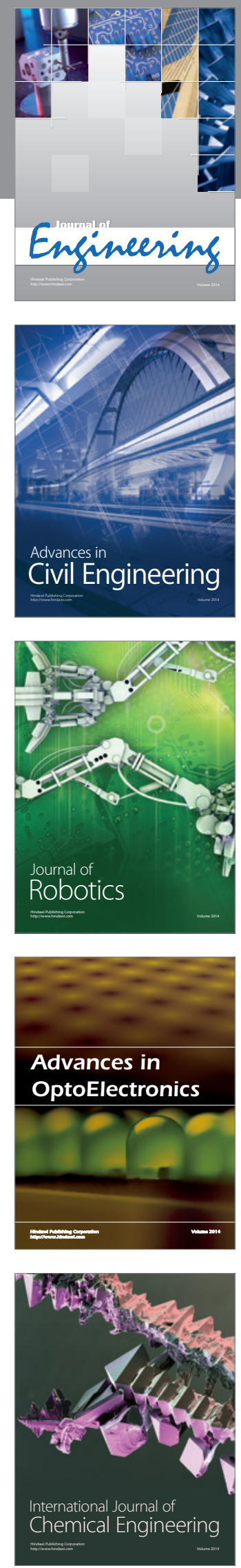

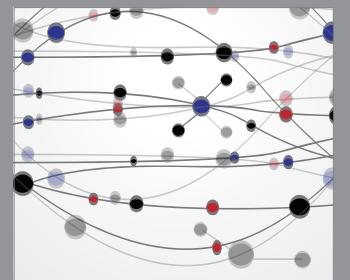

The Scientific World Journal
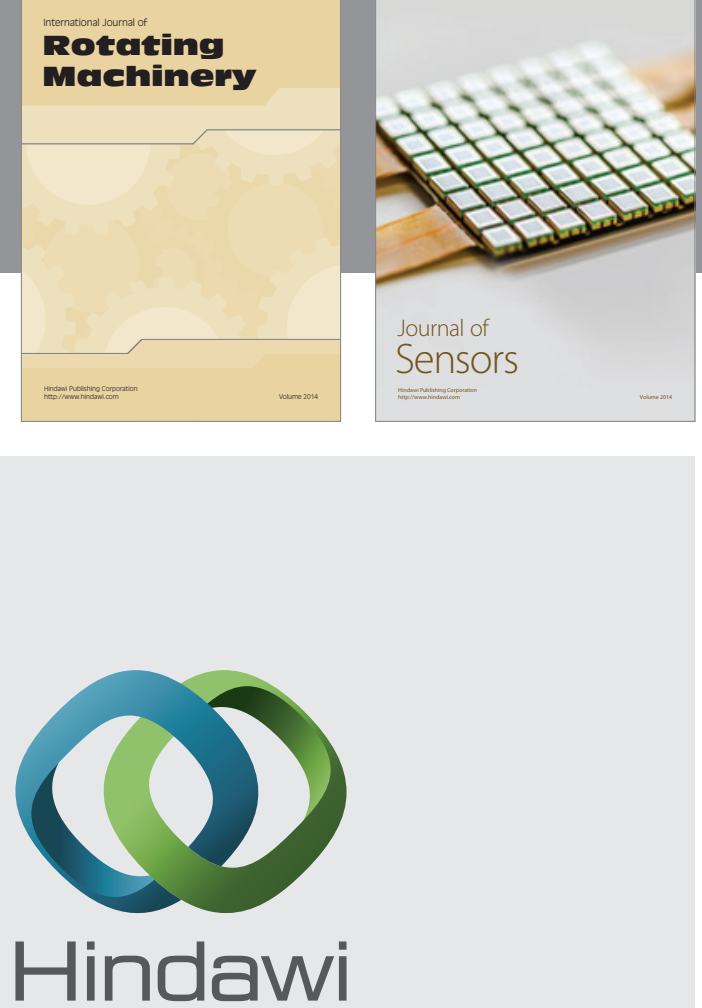

Submit your manuscripts at http://www.hindawi.com
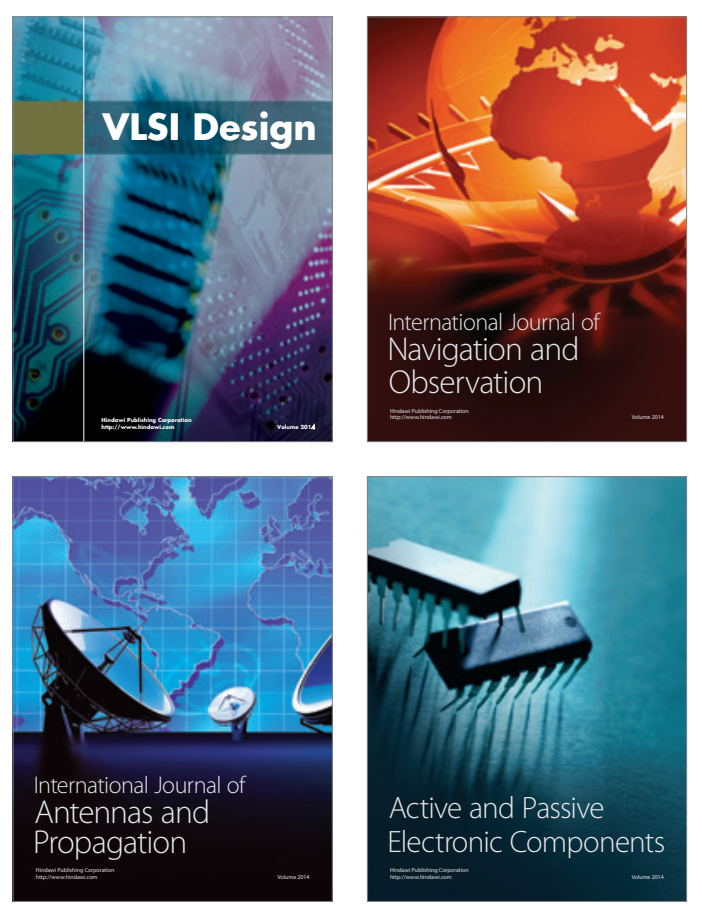
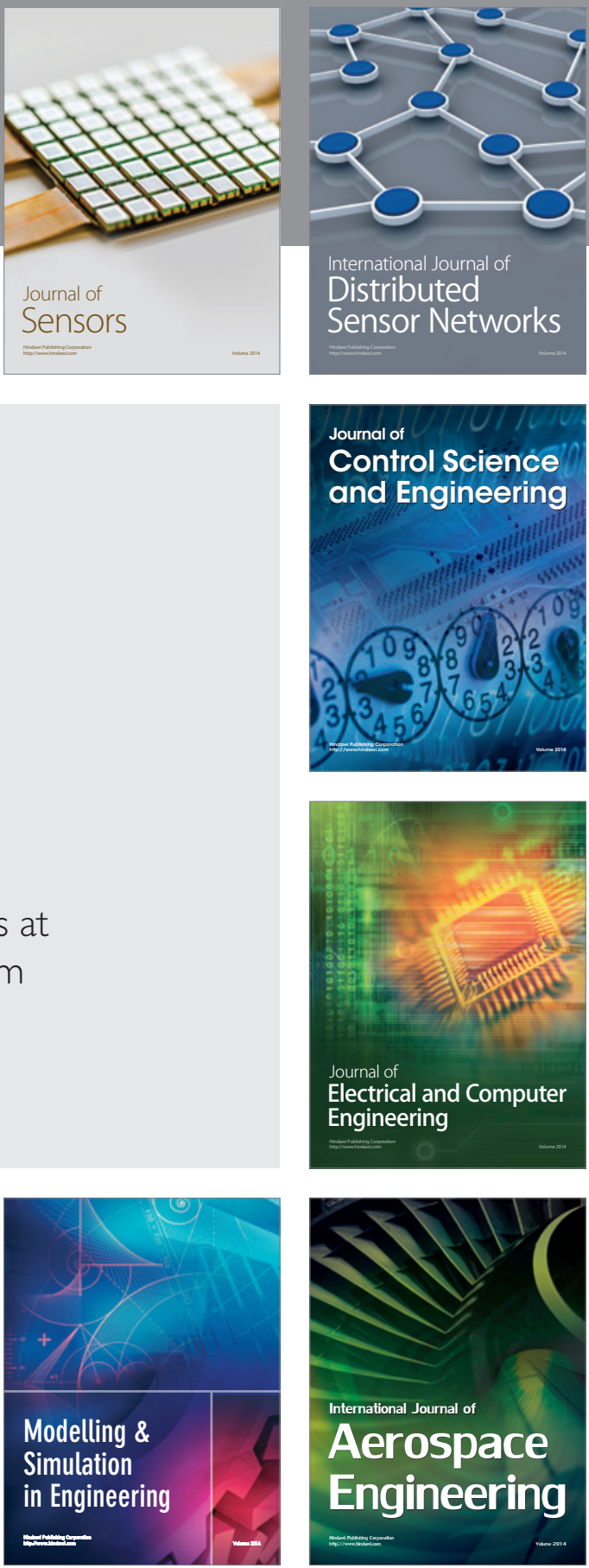

Journal of

Control Science

and Engineering
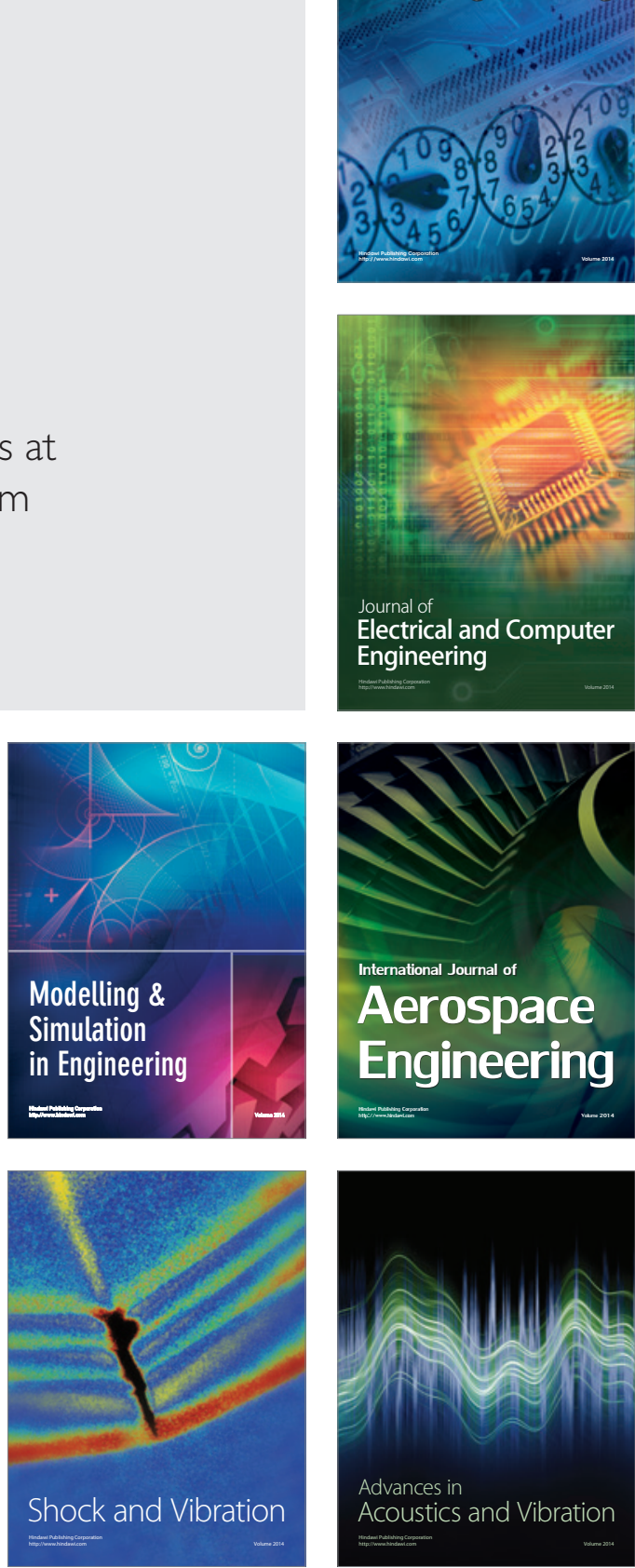